\title{
Differentiated approach to the development of speed-strength capabilities of qualified Muay-Thai athletes, taking into account weight categories Enfoque diferenciado para el desarrollo de las capacidades de velocidad y potencia de atletas del boxeo tailandés teniendo en cuenta las categorías de peso
}

\author{
Stanislav E. Podhurskyi, lurii A. Pavlenko \\ National U niversity of U kraine on Physical Education and Sport (U kraine)
}

\begin{abstract}
The purpose of the study was to identify statistically significant differences in shifts in the indicators of the special working capacity of qualified M uay-Thai athletes in the experimental and control groups of different weight categoriesduring performance of striking techniques using specialised tests. The data from special and scientific literature was considered. A practical experiment was carried out using the Hykso portable strain gauge diagnostic tool. The method of mathematical statistics was used. Forty-five qualified athletes took part in the experiment, twenty-three of whom were included in the experimental group, twenty-two - in the control group, both with and without weight categories. The shifts in the growth of the speed and strength potential of the athletes from the experimental group in comparison with the athletes from the control group of the lightweight category was identified. They are noted in three types of specialised tests of anaerobic capabilities with creatine-phosphate and glycolytic mechanisms of energy supply, in the form of speed and strength components, each separately. The effectiveness of differentiated programs with the use of the Podhurskyi's weight modified sports equipment for the improvement and implementation of speed-strength capabilities of qualified Muay-Thai athletes of different weight categories was established.
\end{abstract}

Keywords: Hykso strain gauge device, pedagogical experiment, Podhurskyi's weight, specialised tests, striking techniques.

Resumen. El objetivo del estudio fue revelar diferencias significativas y confiables en los cambios en los indicadores de capacidad de trabajo especial de los atletas de boxeo tailandés calificados de los grupos experimental y de control, teniendo en cuenta las categorías de peso durante la ejecución de técnicas de percusión utilizando pruebas especial izadas. Se realizó el análisis de datos de literatura especial y científica. Se llevó a cabo un experimento práctico utilizando el dispositivo de diagnóstico portátil de galgas extensométricas «H ykso». Se utilizó el método de estadística matemática. En el experimento participaron cuarenta y cinco atletas calificados, veintitrés de los cuales fueron incluidos en el grupo experimental, veintidós en el grupo de control, tanto con categorías de peso como sin ellas. Se revelaron cambios en el crecimiento de la real ización del potencial de velocidad y potencia de los atletas del grupo experimental que los atletas del grupo de control de la categoría de peso ligero. Se observaron en tres tipos de pruebas especializadas de capacidades anaeróbicas con fosfato de creatina y mecanismos gl ucolíticos de suministro de energía, en forma de componentes de velocidad y fuerza, cadauno por separado. Se estableció la efectividad de los programas diferenciados con el uso del equipo deportivo modificado «Peso de Podgursky» en la mejora e implementación de las capacidades de velocidad y potencia de los atletas de boxeo tailandés calificados de diferentes categorías de peso.

Palabrasclave: gal ga extensométrica «Hykso», experimento pedagógico, Peso de Podgursky, pruebas especializadas, técnicas de choque.

\section{Introduction}

Thestudy of the structure of sportstraining of various types of single combats made it possible to reveal both the differences and the common features of the considered indicators. Namely, the indicators of speedstrength orientation were «explosive» strength and strength endurance familiar for all single combats [1].

Fecha recepción: 25-09-20. Fecha de aceptación: 11-11-20

Stanislav E. Podhurskyi

s. podhurskyi5201-1@ ubogazici.in
«Explosive» strength is understood as the ability to develop the greatest strength in the shortest time during the work of creatine-phosphate energy supply. Strength endurance is the ability to withstand fatigue when working in submaximal power without a significant loss in the force of muscle contractions using the mechanism of glycolytic energy supply [2]. An effective means of determining the degree of training of athletes in single combats of speed-strength orientation are specialised tests «single strike», «series of strikes in 8 and 40 seconds». The indicators of these 
tests demonstrate the level of creatine phosphate and glycolytic performance [3]. At the beginning of the pedagogical experiment, it was necessary to ascertain significant differences in the indices of the special working capacity of the speed-strength orientation of qualified athletes of different weight categories. U pon completion of the experiment, it is necessary to identify or refute the effectiveness of an innovative approach to improve and implement speed-strength abilities among athletes of all weight categories, using differentiated programs and, as an additional burden, the Podhurskyi's weight sports equipment.

Practical application of all these specialised tests in order to improve or reveal the effectiveness of new approaches to thetraining process can be found in boxing. Both among men, in the development of a system for assessing special physical fitness [3], and for women, in order to determine the peculiarities of the implementation of special working capacity of qualified female boxers in conditions of anaerobic power when using creatine-phosphate and glycolytic mechanisms of energy supply [4]. In kickboxing, using the test «single strike», the power indices of selected strikes with the lower extremities were determined with the settings «fast» and «strong», athletes of different sports qual ifications [5]. In taekwondo, using tests of creatine phosphate performance, the speed of movement of the lower limbs was determined [6]. In Muay-Thai, there areexamples of the use of specialised testswith indicators of creatine-phosphate performance, in order to conduct a comparative analysis of special performance among athletes of mass sports categories, before and after a pedagogical experiment [7], the development of a scientifically grounded methodology of training power and speed-power abilities [8]. Also, a model for the use of tests of general and special physical fitness has been developed, in order to identify the leading components of general and special physical fitness of qualified athletes in the lightweight category, also before and after the pedagogical experiment [9].

Analysis of special and scientific literature, generalisation and systematisation of the material, consists in the analytical work of previous studies and papers on a similar topic in combat sports. Having revealed the insufficient volume or even the absence of scientific and experimental material of this topic in the sports training of Muay-Thai, we confirm the relevance of the upcoming research. We also form the structure and sequence of achieving the set goal, with the specified means and methods. The aim of the study is to reveal the difference in shifts of the indices of specialised tests of qualified Muay-Thai athletes in the experimental and control groups, taking into account weight categories.

\section{M aterials and methods}

W ith the help of specialised tests in the ascertaining experiment of scientific research, there were revealed statistically significant differences in speed-strength capabilities between qualified Muay-Thai athletes of different weight categories [10]. Upon completion of the ascertaining experiment, the athletes were divided into two groups: experimental and control. Theindicated groups of athletes in the formative experiment will be compared with each other with and without weight categories. The formative experiment is aimed at revealing the effectiveness of the innovative approach to the training of the experimental group by means of statistically significant differences in the indicator shifts in specialised tests.

Upon completion of the ascertaining experiment, for athletes of different weight categories of the experimental group, differentiated programs for special physical training were developed, taking into account the peculiarities of the complex implementation of the speed-power capabilities of each weight category. Also, as an additional means of burdening to improve speedpower capabilities, the use of a modified two-handed Podhurskyi's weight sports equipment [11] (Figure 1) is proposed. The use of the Podhurskyi's weight is based on the methodology for the development and increase of the motor and functional capabilities of the athlete's body, due to the specifics of Muay-Thai [12].
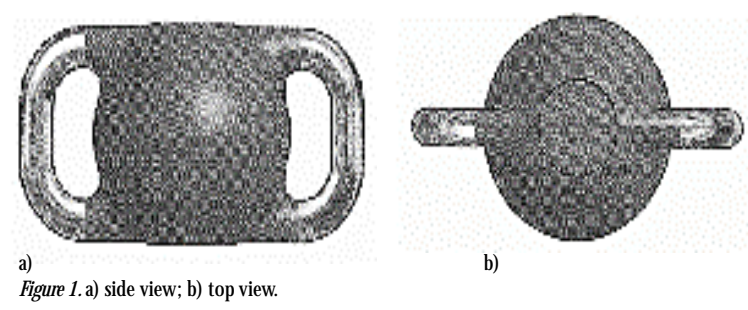

The research program used means of physical influence with its own weight, additional burdening (no more than $50 \%$ of its own weight), and work with a partner. The modes of physical activity used include plyometric (shock) and isotonic, which are concentric and eccentric in nature. Isometric mode (static) in a stationary form, and mixed in a static-dynamic mode. The technique of the competitive activity of M uay-Thai involvestheinclusion of the upper and lower extremities for striking techniques, as well as wrestling in a clinch, 
to perform twisting or takedown on the opponent. Based on this, physical exercises in combination with striking techniques are distributed according to muscle groups of the upper limbs and shoulder girdle, lower limbs and core muscles. The structure of the implementation of each approach implies a sequence of performing physical exercise, the impact of which is directed to the leading muscle groups participating in the striking and wrestling techniques of M uay-Thai, with the subsequent transition to a special preparatory exercise or clinch, which, in accordance with the kinematic and dynamic characteristics, correspond to competitive exercises.

Exercises with own weight or additional weights (Podhurskyi's weight), is carried out in half the amplitude, wherethe «upper» component is responsible for increasing the strike power, the «lower» component is responsible for the power of work in the clinch (half of the action - to the middle and back to the starting position), and full amplitude, for speed and power endurance. Further, without a rest-pause, performing striking techniques or clinching, the duration of which is in the time range equal to the previously performed physical exercise for each weight category, with the condition that when performing the technique, the speed is not reduced and the structure of execution is not distorted. Also, the running time of the physical exercise varies depending on the difficulty level of the exercise itself. The duration of the exercise increases with the decreasing weight category. For heavyweights, this time period should not exceed 40 seconds, for middleweights - 50 seconds and lightweights- 60 seconds. For example, jumps in place with a high hip lift in combination with the straight-knee kick, are performed for 20 seconds for heavyweights, 25 seconds for middleweights, and 30 seconds for lightweights. The rest interval between repetitions of combinationsshould not exceed 30 seconds, and the pause between different combinations, varies from 1 minute 15 seconds to 2 minutes, depending on the weight category. The volume of repetitions of each combination and the number of the combinations themselves are regulated by the coach in accordance with the goals and objectives of sports training.

An example of the selectivity of a load of physical impact on the muscle groups involved in the strikes of the upper and lower extremities is the method of performing physical exercises, with a shift in the centre of gravity. When performing push-ups, squatting, the exercises are performed with the body shifted to one or another limb, left, right, forward, backward, in a straight line or diagonally. The displacement of the body can be fixed from the initial position, or dynamic when performing a motor action. The variability of the amplitude of the motor action should be considered according to the lower, upper or complete structure, which al so affects the nature of the load and the increase in selected physical qualities.

Also, the selectivity and direction of the load include exercises for the upper limbs, the initial position of which is a multilevel setting of the hands (push-ups) in the initial position. Where the initial position of the «leading» hand depends on the type of shock (straight, side, overhand, bottom). Levels in such push-ups mean the location of the hands at chest level (lateral, straight), at head level (overhand), at waist level (below). Such a system looks as follows: when practicing a hook, the «leading» hand in the lying position is set aside at chest level, and the «auxiliary» hand is at the body. At the same time, the legs are shifted towards the "auxiliary» hand and the body towards the «leading» hand. Thus, when performing push-ups, the «leading» hand will be loaded to the maximum. U pon completion of the exercise, a hook is performed with the «leading» hand. Exercising with a partner, in combination with the subsequent transition to a special preparatory exercise, allows to selectively distribute and increase the load on specific muscle groups. In the first case, the partner acts as an assistant in the form of support, when the exercise is performed with a «loss of fulcrum point», that is, in an inclined stance in resting contact upon the partner with hands, body, or head, also upside down, with contact on the partner with one or two feet. In the second case, the partner exerts an additional load on a specifically selected muscle group by applying pressure with tension or with his body weight.

Also, the research program used the «progressionregression» method of the number of repetitions of physical exercises and the time interval of striking techniques in a single combination. The amount of activity is regulated in accordance with the athletes' weight category. For example: push-ups from the floor with a narrow setting of the hands from 1 time (heavyweights); 2 times (middleweights); 3 times (lightweights); up to 5 times (heavyweights); 6 times (middleweights); 7 times (lightweights) and the reverse; straight punches from 10 seconds (heavyweights); 12 seconds (middleweights); 14 seconds (lightweights); up to 18 seconds (heavyweights); 20 seconds (middleweights); 22 seconds (lightweights) and the reverse. In conclusion, in order to increase and implement the speed-strength potential of athletes, the 
research program tested the methods of «mini rounds» and «blitz».

The principle of the «mini rounds» method is to conduct a certain number of rounds in the form of shadowboxing, in the intervals between which physical exercises are performed in accordance with the striking techniques performed in the round. The duration of the round is 60 seconds, and the physical exercise according to the weight category: 20 seconds, 25 seconds, 30 seconds. Rest interval between combinations of exercise and mini round, time remaining after exercise: 40 seconds, 35 seconds, 30 seconds. An example of how this method works: the first and last rounds act as a warm-up and cool-down. After the first round, performing the exercise on the lower limbs, after some rest, a round on striking techniques of the lower limbs. Further exercises on the body and a round of work in the clinch. Further exercise on the upper limbs and a round with striking hand techniques. After the cycle is repeated: legs, body, arms. The number of cycles is determined by the coach, in accordance with the goals and objectives of training.

The principle of the «blitz» method is that during one minute, athletes perform several repetitions of combinations of physical exercises and striking techniques with maximum speed. For heavyweights, the combination is 5 seconds +5 seconds; middleweights 7 seconds +7 seconds; lightweights 10 seconds +10 seconds. Based on the indicated time, it follows that for athletes in the heavyweight category it is approximately six repetitions of combinations, for middleweights, it is four repetitions, and three repetitions for lightweights. Taking into account the previous studies of foreign experts in the issue of the temporal structure of exercise and the rest-pause of the speed-strength orientation of various combat sports, the authors came to the conclusion that an equal work-pause ratio should be observed in Muay-Thai. Therefore, upon completion of differentiated programs in the form of combinations of physical exercises in unity with striking techniques, it is recommended to use short-term series of striking techniques in working with special implements (Thai bag, punching bag, wall punching pad) up to three cycles of each type of strikes. In the research program, changes were made taking into account weight categories, in the form of «work - 4 seconds, rest - 4 seconds» for heavyweights; «work - 6 seconds, rest - 6 seconds» for middleweights; «work - 8 seconds, rest - 8 seconds» for lightweights. The rest interval between the series of each type of strike, no more than 2 minutes, taking into account the weight categories. The authors called such series «combat intervals» [13-16]. Each of the presented methods of the research program contributed to the increase in the speed-strength capabilities of athletes, both in the unity of the speed and strength components and individually.

For the athletes from the control group, the traditional method of increasing and implementing the speed-strength abilities of qualified Muay-Thai athletes was applied. In the traditional M uay-Thai program, all types of physical work modes are al so used: plyometric, isotonic, isometric, static-dynamic, both with and without weight. But in contrast with the research program, there is no differentiated approach according to the time intervals of physical work and rest pauses tied to specific weight categories. There is no practice of compiling combinations of physical exercises and striking techniques, similar in structure and neuromuscular efforts, into a single whole. N one of the methods are applied in the above forms, taking into account weight categories. In the formative experiment, as well as in the ascertaining study, the Hykso portable strain gauge diagnostic tool [17] was used (Figure 2). In mathematical estimation, the data on power indicators and the number of strikes in specialised tests were used. In the specialised test «single strike» W 1 , in the special ised test «series of strikes in 8 seconds» $W$ NS8, in the specialised test «series of strikes in 40 seconds» W 40 and NS40.

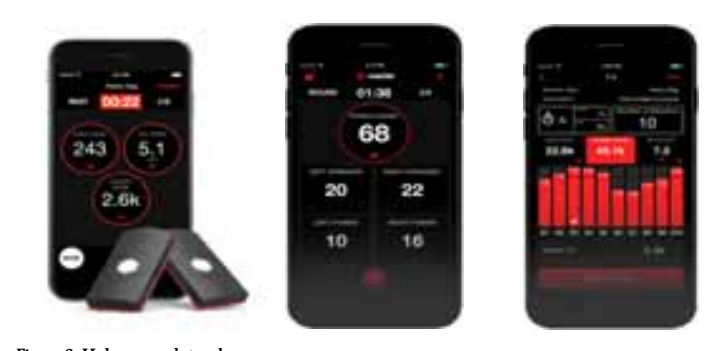

Figure 2. Hykso punch trackers.

For a practical experiment, forty-five qualified athletes of all weight categories were accepted, conditionally divided into two groups: experimental (EG) and control (CG). Twenty-three participants were included in $E G$, of which eight were athletes in the lightweight and heavyweight categories, and seven were in middleweight categories. Twenty-two were included in CG, of which seven are lightweights and middleweights, and eight are heavyweights. The procedure for the practical conduct of specialised tests is identical to that used in the ascertaining experiment [10]. The weight of boxing gl oves was selected according 
to the weight of athletes, in the ratio of 10,12, and 14 ounces, respectively, in the light, medium and heavy categories. For each group of striking techniques, a special means for striking was selected. For roundhouse kicks, theThai bag was used, a suspended large punching bag for a straight knee strike with an emphasis on the punching bag, and for a straight kick, horizontal elbow, side and straight punches, respectively, a wall punching pad. The selection of striking techniques for conducting specialised tests was made based on the result of pedagogical observation of the expert group [18]. Method of mathematical statistics was carried out. Mathematical processing was performed on a personal computer using the standard statistical package STATISTICA 10.0 portable. The Student'st-test method was applied for related populations in order to determine the statistical significance of differences in the shifts in the indicators of special ised tests obtained during the experiment.

\section{Results}

The results of the formative experiment between the experimental and control groups, both with and without weight categories, are presented, respectively, in Tables 1, 2, 3, and 4. The findings are based on the difference in the indices of striking techniques and the total number of strikes of qualified Muay-Thai athletes in each of three specialised tests before and after the practical experiment. Thus, differences were revealed in the shifts of special performance indicators in the form of strike power (W 1, W 8, W 40) and the total

Table 1

Shifts of indicators of special working capacity of athletes in the experimental and control groups, $X \pm m$

\begin{tabular}{|c|c|c|}
\hline \multirow{2}{*}{ Specialised tests } & \multicolumn{2}{|c|}{ Groups of athletes } \\
\hline & Experimental group & Control group \\
\hline Straight Knee Strike, W 1, arb. units & $1.72 \pm 0.92$ & $0.31 \pm 0.42$ \\
\hline Straight Kick, W 1, arb. units & $-0.19 \pm 0.78$ & $-0.86 \pm 0.72$ \\
\hline Horizontal Elbow, W 1, arb. units & $1.46 \pm 0.61$ & $0.89 \pm 0.33$ \\
\hline Roundhouse Kick, W 1 , arb. units & $4.73 \pm 1.88^{*}$ & $-0.29 \pm 1.20^{*}$ \\
\hline Down Roundhouse Kick, W 1, arb. units & $5.59 \pm 2.03$ & $2.15 \pm 0.51$ \\
\hline Left Jab, W 1, arb. units & $2.11 \pm 0.63^{*}$ & $0.15 \pm 0.36^{*}$ \\
\hline Right Jab, W 1, arb. units & $0.80 \pm 0.28$ & $0.96 \pm 0.25$ \\
\hline Left Hook, W 1, arb. units & $1.88 \pm 1.06$ & $0.32 \pm 0.28$ \\
\hline Right Hook, W 1 , arb. units & $4.33 \pm 1.02^{*}$ & $0.70 \pm 0.95 *$ \\
\hline Series of Hooks 8, W 8, arb. units & $53.83 \pm 16.83$ & $31.45 \pm 11.58$ \\
\hline Number of strikes, N S8, times & $6.48 \pm 0.86^{*}$ & $3.45 \pm 0.57 *$ \\
\hline Straight Knee Strike 8, W 8, arb. units & $32.70 \pm 7.56 *$ & $11.14 \pm 6.27 *$ \\
\hline Number of strikes, N S8, times & $2.74 \pm 0.46^{*}$ & $1.50 \pm 0.44^{*}$ \\
\hline Horizontal Elbow 8, W 8, arb. units & $37.32 \pm 9.45^{*}$ & $14.92 \pm 5.39 *$ \\
\hline Number of strikes, N S8, times & $0.22 \pm 0.30$ & $-0.41 \pm 0.38$ \\
\hline Down Roundhouse Kick 8, W 8, arb. units & $40.96 \pm 18.90$ & $38.55 \pm 13.86$ \\
\hline Number of strikes, N S8, times & $1.96 \pm 0.41$ & $1.23 \pm 0.45$ \\
\hline Roundhouse Kick 8, W 8, arb. units & $51.04 \pm 14.43$ & $29.55 \pm 9.79$ \\
\hline Number of strikes, N 58 , times & $0.35 \pm 0.44$ & $-0.36 \pm 0.31$ \\
\hline Series of $J$ abs $8, W$, arb. units & $63.52 \pm 17.76$ & $30.27 \pm 9.82$ \\
\hline Number of strikes, N S8, times & $6.17 \pm 1.22^{*}$ & $2.86 \pm 0.86^{*}$ \\
\hline Straight Kick 8, W 8, arb. units & $-113.30 \pm 4.34$ & $-101.64 \pm 7.00$ \\
\hline Number of strikes, N S8, times & $0.48 \pm 0.36$ & $-0.32 \pm 0.33$ \\
\hline Series of Hooks 40, W 40 , arb. units & $133.00 \pm 38.91$ & $78.05 \pm 39.04$ \\
\hline Number of strikes, N S40, times & $30.00 \pm 6.12$ & $26.45 \pm 7.35$ \\
\hline Series of Jabs 40, W 40 , arb. units & $93.09 \pm 25.24 *$ & $33.77 \pm 6.04 *$ \\
\hline Number of strikes, N S40, times & $25.48 \pm 5.94$ & $18.50 \pm 6.91$ \\
\hline
\end{tabular}

number of strikes (NS8, NS40) in thezones of maximum and submaximal power, when performing specialised tests of qualified athletes of different weight categories.

Based on the estimations from Table 1 we see a statistical significance in the shifts of indicators according to the Student's t-criterion in six striking techniques and three types of specialised tests between athletes in the experimental and control groups. Striking techniques for the «single strike» test include «Roundhouse Kick» $(P<0.05)$, «Left Jab» $(P<0.01)$, «Right Hook» $(P<$ 0.05). The striking techniques of the test «series of strikes in 8 seconds» include «Straight Knee Strike 8» $(P<$ 0.05), «Horizontal Elbow 8» $(P<0.05)$. Striking techniques for the test «series of strikes in 40 seconds» include «Series of Jabs 40» $(P<0.05)$. Regarding the indicators of the total number of strikes in the specialised test "series of strikes in 8 seconds", three cases of statistically significant differences were revealed. The number of punches in the striking techniques «Series of Hooks 8» $(P<0.01)$, «Straight Knee Strike 8» $(P<$ $0.1)$, «Series of Jabs 8 » $(P<0.05)$.

In the table, the experimental and control groups have been compared without taking into account the weight categories. The revealed shifts of indicators in favour of the athletes from the experimental group in the test «single strike» consists in the growth of the complex manifestation of the speed-strength orientation in the form of the unity of the speed component expressed in the starting force in the range of the first 50-100 $\mathrm{m} / \mathrm{s}$, and the force component expressed in explosive strength in the range of $300-500 \mathrm{~m} / \mathrm{s},(4.73$ $>-0.29) ;(2.11>0.15) ;(4.33>0.70)$. Relative to the specialised test «8 seconds», the difference in the shifts of indicators is also due to the growth of the speedstrength manifestation of the athletes from the experimental group in a single complex of speed and strength components. This is indicated by statistically significant shifts in indicators as power $(32.70>11.14)$; (37.32 > 14.92), and the total number of strikes delivered in the «Straight Knee Strike 8» technique $(2.74>1.50)$. At the same time, it should be noted that in the striking techniques «Series of Hooks 8 » and «Series of Jabs 8» there are no statistically significant differences in the shifts of power indicators, but in the total number of punches delivered - there is $(6.48>3.45)$; $(6.17>2.86)$, which indicates a greater increase in the velocity component. A similar explanation is given to the shift in the index of the technique «Series of Jabs 40» $(93.09>33.77)$, where the shift in the power indices was detected, but not in 
the total number of strikes. In this case, the emphasis of the growth of speed-strength is shifted towards the strength component. The revealed shifts in the growth of the implementation of the speed-power potential of the athletes from the experimental group relative to the results of the athletes from the control group are noted in three types of specialised tests of anaerobic capabilities with creatine-phosphate and glycolytic mechanisms of energy supply.

\begin{tabular}{|c|c|c|}
\hline \multirow[b]{2}{*}{ Special ised tests } & \multirow{2}{*}{\multicolumn{2}{|c|}{ Groups of lightweight athletes }} \\
\hline & & \\
\hline Straight Knee Strike, W 1, arb. units & $1.63 \pm 1.62$ & $-0.43 \pm 0.70$ \\
\hline Straight Kick, W 1 , arb. units & $-0.71 \pm 1.57$ & $\begin{array}{l}-0.43 \pm 0.10 \\
-1.99 \pm 2.18\end{array}$ \\
\hline Horizontal Elbow, W 1, arb. units & $2.77 \pm 1.38$ & $1.69 \pm 0.70$ \\
\hline Roundhouse Kick, W 1, arb. units & $1.06 \pm 0.56$ & $-1.86 \pm 3.77$ \\
\hline Down Roundhouse Kick, W 1, arb. units & $0.31 \pm 1.43$ & $2.17 \pm 1.23$ \\
\hline Left Jab, W 1, arb. units & $2.35 \pm 0.88 *$ & $-0.20 \pm 0.38 *$ \\
\hline Right Jab, W 1, arb. units & $0.31 \pm 0.65$ & $0.64 \pm 0.28$ \\
\hline Left Hook, W 1, arb. units & $3.69 \pm 1.90$ & $0.71 \pm 0.70$ \\
\hline Right Hook, W 1, arb. units & $4.81 \pm 2.00 *$ & $-1.29 \pm 1.50 *$ \\
\hline Series of Hooks 8, W 8 , arb. units & $21.38 \pm 22.21$ & $0.57 \pm 7.58$ \\
\hline Number of strikes, N S8, times & $4.50 \pm 1.56$ & $2.71 \pm 1.37$ \\
\hline Straight Knee Strike 8, W 8, arb. units & $31.13 \pm 11.18$ & $21.57 \pm 19.55$ \\
\hline Number of strikes, N S8, times & $2.88 \pm 0.82$ & $2.71 \pm 0.90$ \\
\hline Horizontal Elbow 8, W 8, arb. units & $61.13 \pm 25.24 *$ & $11.29 \pm 8.95 *$ \\
\hline Number of strikes, N S8, times & $0.63 \pm 0.45$ & $0.43 \pm 1.08$ \\
\hline Down Roundhouse Kick 8, W 8, arb. units & $3.00 \pm 21.50$ & $60.00 \pm 39.83$ \\
\hline Number of strikes, N S8, times & $1.75 \pm 0.96$ & $0.29 \pm 0.61$ \\
\hline Roundhouse Kick 8, W 8, arb. units & $30.13 \pm 19.52$ & $23.86 \pm 13.89$ \\
\hline Number of strikes, N S8, times & $-0.75 \pm 0.78$ & $-0.14 \pm 0.37$ \\
\hline Series of Jabs 8 , W 8 , arb. units & $49.88 \pm 19.68$ & $16.86 \pm 7.95$ \\
\hline Number of strikes, N S8, times & $5.38 \pm 2.18^{*}$ & $0.57 \pm 0.94 *$ \\
\hline Straight Kick 8, W 8, arb. units & $-100.00 \pm 8.75$ & $-68.86 \pm 15.34$ \\
\hline Number of strikes, N S8, times & $0.13 \pm 0.59$ & $0.14 \pm 0.94$ \\
\hline Series of Hooks 40 , W 40, arb. units & $71.88 \pm 21.45$ & $-22.86 \pm 75.42$ \\
\hline Number of strikes, N S40, times & $16.75 \pm 11.40$ & $5.43 \pm 4.12$ \\
\hline Series of $\mathrm{Jabs} 40, \mathrm{~W} 40$, arb. units & $58.13 \pm 16.48^{*}$ & $17.29 \pm 5.40^{*}$ \\
\hline Number of strikes, N S40, times & $13.38 \pm 14.48$ & $2.29 \pm 6.10$ \\
\hline
\end{tabular}

Based on the estimations from Table 2, we see significant reliability in the shifts of indicators by the Student'st-criterion in four striking techniques and three types of specialised tests between athletes in the experimental and control groups. Striking techniques of the «single strike» test include «Left Jab» $(P<0.05)$, «Right Hook» $(P<0.05)$. The striking techniques of the test «series of strikes in 8 seconds» include «Horizontal Elbow 8 » $(P<0.1)$. Techniques of the test «series of strikes in 40 seconds» include «Series of Jabs 40» ( $P<$ 0.05). Regarding the indicators of the total number of strikes delivered in the specialised test «series of strikes in 8 seconds», one case of statistically significant differences was revealed. The number of strikes in the «Series of Jabs» $(P<0.1)$. Since the athletes belong to the lightweight category, the difference in the shifts of the indicators of the athletes of the experimental group in comparison with the athletes from the control group in the test «single strike» is the increase in the speed component expressed in the starting force in the range of the first $50-100 \mathrm{~m} / \mathrm{s},(2.35>-0.20) ;(4.81>-1.29)$. Relative to the specialised test « 8 seconds», the difference in the shifts of indicators in favour of the athletes from the experimental group due to the growth of the strength component in the form of explosive force in the range of $300-500 \mathrm{~m} / \mathrm{s},(61.13>11.29)$, as indicated by the absence of shifts of the total number of strikes.

At the same time, it should be noted that there are no significant differences in the shifts of the power indices in the «Series of Jabs 8 », but there is $(5.38>0.57)$ in the total number of strikes, which indicates a greater increase in the velocity component. A similar explanation is given to the shift in the index of the technique «Series of Jabs 40 » (58.13 > 17.29), where the shift in the power indices was detected, but not in the total number of strikes. In this case, the emphasis of the growth of speed-strength manifestation is shifted towards the strength component. The reveal ed shifts in the growth of the implementation of the speed-strength potential of the athletes from the experimental group in comparison with the athletes of the control group of the lightweight category are noted in three types of special ised tests of anaerobic capabilities with creatinephosphate and glycolytic mechanisms of energy supply.

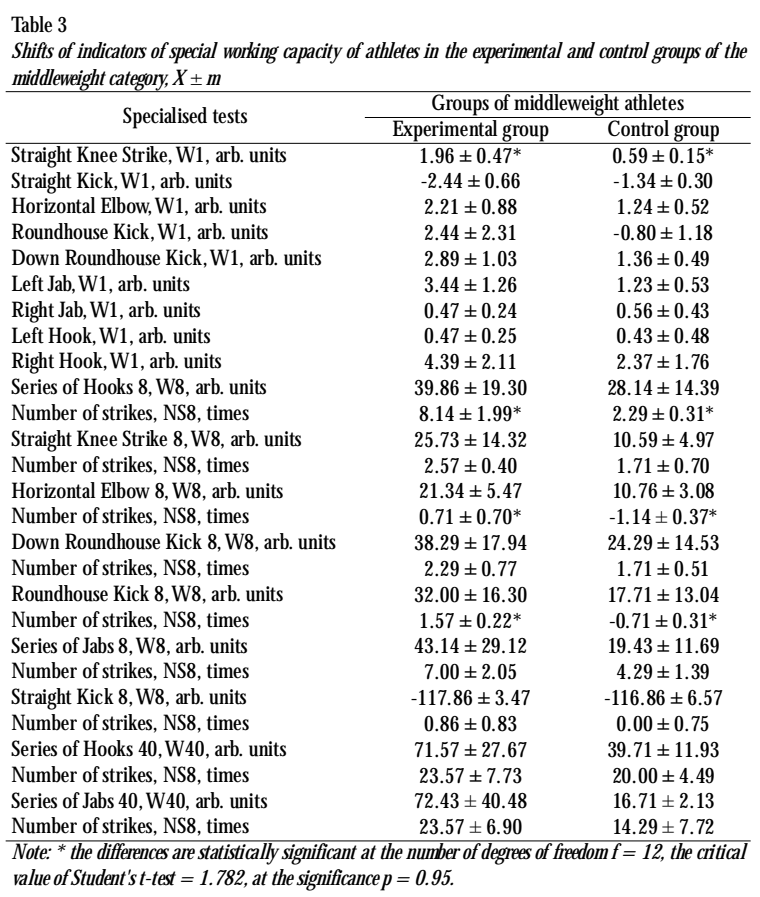

Based on the estimations from Table 3, we see significant reliability of the shifts of indicators according to the Student's t-criterion in one technique of the specialised test «single strike» and three indicators of the total number of hits of the special ised test «8 seconds» between athletes in the experimental and control groups of the middleweight category. The «single strike» test is referred to as «Straight Knee Strike» $(P<0.05)$. 
Since the athletes belong to the middleweight category, the difference in the shifts of the indicators of the athletes from the experimental group in comparison with the athletesfrom the control group in the test «single strike» consists in the growth of the complex manifestation of the speed-strength orientation in the unity of the speed and strength components $(1.96>0.59)$. In the test «8 seconds» in the striking techniques "Series of Hooks 8», «Horizontal Elbow 8», «Roundhouse Kicks 8», differences in the shifts of indicators of the total number of strikes were determined $(P<0.05)$; $(P<0.05)$; $(P$ $<0.001)$ and the absence of differences in power indices, which indicates an increase in the indices of speedstrength orientation with an emphasis on the speed component, $(8.14>2.29)$; $(0.71>-1.43)$; $(1.57>$ $0.71)$. The revealed shifts in the growth of the implementation of the speed-power potential of the athletes of the experimental group in comparison with the athletes from the control group of the middleweight category are noted in two types of specialised tests with the general creatine-phosphate mechanism of energy supply. However, in the mode of anærobic glycolytic capabilities, the shifts in the growth of the speed-strength potential of athletesare insignificant, thustheir indicators did not provide statistically significant differences.

Table 4

Shifts of indicators of special working capacity of athletes in the experimental and control groups of the heavyweight category, $X \pm m$

\begin{tabular}{|c|c|c|}
\hline \multirow{2}{*}{ Special ised tests } & \multicolumn{2}{|c|}{ Groups of heavyweight athletes } \\
\hline & Experimental group & Control group \\
\hline Straight Knee Strike, W 1, arb. units & $1.61 \pm 2.37$ & $0.71 \pm 1.05$ \\
\hline Straight Kick, W 1, arb. units & $2.30 \pm 1.19$ & $0.54 \pm 0.78$ \\
\hline Horizontal Elbow, W 1, arb. units & $-0.53 \pm 0.40$ & $-0.13 \pm 0.37$ \\
\hline Roundhouse Kick, W 1, arb. units & $10.40 \pm 4.73 *$ & $1.52 \pm 0.77 *$ \\
\hline Down Roundhouse Kick, W 1, arb. units & $13.24 \pm 4.78^{*}$ & $2.81 \pm 0.96 *$ \\
\hline Left Jab, W 1, arb. units & $-0.17 \pm 0.38$ & $-0.47 \pm 0.79$ \\
\hline Right Jab, W 1, arb. units & $1.59 \pm 0.40$ & $1.60 \pm 0.52$ \\
\hline Left Hook, W 1, arb. units & $1.31 \pm 2.55$ & $-0.11 \pm 0.36$ \\
\hline Right H ook, W 1, arb. units & $3.81 \pm 1.70$ & $0.98 \pm 1.78$ \\
\hline Series of Hooks 8, W 8, arb. units & $98.50 \pm 38.81$ & $61.38 \pm 28.14$ \\
\hline Number of strikes, NS8, times & $7.00 \pm 0.95$ & $5.13 \pm 0.87$ \\
\hline Straight Knee Strike 8, W 8, arb. units & $40.38 \pm 16.49 *$ & $2.50 \pm 5.23 *$ \\
\hline Number of strikes, NS8, times & $2.75 \pm 1.14 *$ & $0.25 \pm 0.52 *$ \\
\hline Horizontal Elbow 8, W 8, arb. units & $27.50 \pm 8.85$ & $21.75 \pm 13.55$ \\
\hline Number of strikes, NS8, times & $-0.63 \pm 0.40$ & $-0.25 \pm 0.34$ \\
\hline Down Roundhouse Kick 8, W 8, arb. units & $81.25 \pm 48.24$ & $32.25 \pm 17.56$ \\
\hline Number of strikes, NS8, times & $1.88 \pm 0.55$ & $1.63 \pm 1.07$ \\
\hline Roundhouse Kick 8, W 8, arb. units & $88.63 \pm 33.55$ & $44.88 \pm 23.08$ \\
\hline Number of strikes, NS8, times & $0.38 \pm 0.95$ & $-0.38 \pm 0.81$ \\
\hline Series of Jabs $8, W 8$, arb. units & $95.00 \pm 43.07$ & $51.50 \pm 24.60$ \\
\hline Number of strikes, NS8, times & $6.25 \pm 2.57$ & $3.63 \pm 1.85$ \\
\hline Straight Kick 8, W 8, arb. units & $-123.63 \pm 8.08$ & $-117.00 \pm 3.43$ \\
\hline Number of strikes, NS8, times & $0.50 \pm 0.64^{*}$ & $-1.00 \pm 0.45^{*}$ \\
\hline Series of Hooks 40 , W 40, arb. units & $247.88 \pm 103.09$ & $199.88 \pm 73.13$ \\
\hline Number of strikes, NS8, times & $48.88 \pm 10.17$ & $50.50 \pm 17.17$ \\
\hline Series of Jabs $40, W$ 40, arb. units & $146.13 \pm 64.03$ & $63.13 \pm 9.09$ \\
\hline Number of strikes, NS8, times & $39.25 \pm 6.98 *$ & $21.29 \pm 2.89 *$ \\
\hline
\end{tabular}

Based on the estimations from Table 4, we see significant reliability of the differences in the shifts of indicators according to the Student'st-criterion in three striking techniques of two types of specialised tests and three indicators of the total number of strikes in the specialised test « 8 and 40 seconds» between athletes in the experimental and control groups of the heavyweight category. Striking techniques for the test «single strike» include, «Roundhouse Kick» $(P<0.1)$, «Down Roundhouse Kick» $(P<0.05)$. The striking techniques for the test «series of strikes in 8 seconds» include «Straight Knee Strike 8» $(P<0.05)$. Ascertaining the difference in the shifts in the indices of the athletes from the experimental group in comparison with the athletes in the control group from the heavyweight category, it should be noted the growth of the strength component in the «single strike» test in the form of explosive force in the range of the first $300-500 \mathrm{~m} / \mathrm{s},(10.40>1.52)$; (13.24 > 2.81). In the test «8 seconds» the growth of the speed-strength performance of athletes lies in the unity of the speed and strength components, (40.38 > 2.50), which isemphasised by the presence of differences in the shifts of the total number of strikes $(2.75>0.25)$. It is worth noting that in the «Straight Kick 8» strike of the specialised «8 seconds» test there are no significant differences in the shifts of the power indicators, but in the total number of strikes delivered there are $(0.50>$ -1.00). A similar ratio is the difference in the shifts of indicators in the striking technique "Series of Jabs 40», where there are no statistically significant differences in the shifts of indices, but in the total number of strikes delivered - there is $(39.25>21.29)$. These features indicate a greater increase in the speed component of the athletes from the experimental group. The revealed shifts in the growth of the implementation of the speedstrength potential in power and the total number of strikes of the athletes from the experimental group of the heavyweight category are noted in three types of specialised tests of anzerobic capabilities with creatinephosphate and glycolytic mechanisms of energy supply.

\section{Discussion}

From the presented tables, it follows that differences in the shifts of power indices and the total number of strikes are present in all types of specialised tests of each weight category of the experimental groups, as well as the experimental group without taking into account weight categories. Describing the positive result of the formative experiment, it should be noted the features of each group of these specialised tests separately and in general. In the special ised test «single strike» of the lightweight category of the experimental group, there is an increase in the speed-strength potential in the «Left Jab» and «Right Hook» striking techniques. It follows from this that in the striking technique with the 
«Left Jab» a positive role is played by the characteristic of lightweight athletes to the performance of a strong single strike, especially the left straight [19], which was demonstrated in the ascertaining experiment [10]. The growth of the speed-strength orientation of the «Right H ook» striking technique indicates the advantage of using the «Left Jab + Right Hook» striking combination for athletes from the lightweight category. The growth of the speed-strength potential in the «Horizontal Elbow 8» striking technique indicates a bal anced improvement of the speed-strength orientation in this technique in lightweight athletes.

This conclusion follows from the fact that in the ascertaining experiment in the zone of anæer obic power of creatine-phosphate energy supply, a high rate of the speed component was shown in the «single strike» test [10]. In the formative experiment, while maintaining the initial state, an increase in the strength component was shown in the same power zone and the mechanism of energy supply in the «8 seconds» test. The statement of a balanced growth of the speed-strength potential of the lightweight category from the experimental group is also confirmed by the presence of a difference in the shifts of the indicators of the same striking technique, only with a different mechanism of energy supply. That is, the growth of the speed component in the striking technique «Series of Jabs 8 » on the basis of a statistically significant difference in the total number of punches delivered, and the power component «Series of Jabs 40 » in the form of a statistically significant difference in the indicator of the strike power. It is important to note that an increase in speed-strength capabilities is expressed in striking techniques with the use of the upper limbs, while indicators in striking techniques with the participation of the lower limbs retained their previous high level, demonstrated in the ascertaining experiment [10].

The growth of the speed-strength potential of the lightweight athletes from the experimental group in the considered striking techniques is manifested in all types of specialised tests, in the form of speed and strength components separately. The growth of the speed-strength potential of the athletes from the middleweight category of the experimental group was revealed in the zone of anæerobic power of creatinephosphate working capacity, while in the zone of anæerobic power of glycolytic working capacity it was not revealed. This phenomenon can be explained by the peculiarity of athletes of middleweight of high motor performance with a tendency to power endurance [20-
22]. This means that qualified athletes of the middleweight category al ready have a rather high level of indicators of the specialised test «40 seconds», which should be increased by other methods of sports training corresponding to the growth of strength endurance.

In the special ised test «single strike», the growth of the speed-strength potential was revealed in the punch technique "Straight Knee Kick», where, due to the specifics of the weight category, the speed and strength components were implemented in a complex manner. Theincrease in speed-strength capabilitiesin thisstriking technique is natural, this is indicated by reliably negative differences in the indicators of this technique in comparison with athletes in the heavyweight category in the ascertaining experiment [10]. In the specialised test «8 seconds» it is worth paying attention to the fact that the increase in the speed component in athletes from the middle weight category of the experimental group was revealed in striking techniques similar in technical structure, in particular, in the «twisting» of the body. This feature gives «hints» to which muscle groups should be paid close attention in order to increase the speed-strength capabilities in practicing the leading striking techniques of Muay-Thai. The growth of the speed-strength potential of athletes of the middleweight category of the experimental group in the noted striking techniques, manifested in specialised tests of creatinephosphate performance, in the form of the unity of the speed and strength components, as well as separately for only the speed component.

In the specialised test «single strike» of the heavyweight category of the experimental group, there is an increase in the speed-strength potential in the «Roundhouse Kick» and «D own Roundhouse Kick» techniques. Due to the specifics of the weight category, the growth of the speed-strength potential is biased towards the strength component. The increase in speedstrength capabilities in thisstriking technique is expected, as indicated by the reliably negative differences in the indicators of these striking techniques in comparison with athletes in the lightweight category in the ascertaining experiment [10]. In the specialised test «8 seconds", an increase in speed-strength capabilities in the unity of strength and speed components is observed in the striking technique "Straight Knee Strike 8». Striking techniques, the structure of which is based on the principle of a small lever, are more effective in manifesting higher speed-strength capabilities for hearyweight athletes, which makes the result of these techniques predictable [10]. The striking techniques 
«Straight Kick 8» and «Series of Jabs 40» of specialised tests «8 and 40 seconds» are united by the fact that in their data there are no reliably significant differences in shifts in power indicators, but in the total number of strikes delivered. These features indicate a greater increase in the speed component of the athletes from the experimental group for these striking techniques. The growth of the speed-strength potential of the athletes in the heavy weight category from the experimental group in the noted striking techniques is manifested in all types of specialised tests, in the form of speed and strength components, both separately and in unity.

Analysing the findings from comparing the shifts in indicators of the experimental and control groups without taking into account weight categories, a number of features should be noted for each specialised test. In the test «single strike» the differences in shifts were revealed for the indices of three striking techniques, the contribution of which was made by the athletes of the lightweight and hearyweight categories of the experimental group, while the indices were registered in the group without taking into account the weight categories. The indicator of athletes in the middleweight category in the «Straight Knee Kick» technique was reduced to a different result, which turned out to be statistically insignificant in the general experimental group.

In the specialised test «8 seconds» it is necessary to pay attention to the fact that the contribution to all ca ses of revealing statistically significant differences in the indicators of striking techniques was made by the athletes of each weight group separately and in unity. The differences in the shifts in the indices of the total number of strikes in «Series of Hooks 8» were revealed due to athletes of the middleweight category. Differences in the shifts of strength indices and the total number of «Straight Knee Strike 8» were revealed due to the athletes of the heavyweight category. The differences in the shifts in the indices of the total number of strikes «Series of Jabs 8» were revealed due to the athletes of the lightweight category. The differences in the shifts of the strength indicators «Horizontal Elbow 8» were revealed due to the athletes of the lightweight category. It is also worth noting that the unity of athletes of all weight categories levelled the differences in the shifts of the indicators of the total number of strikes in the striking techniques «Horizontal Elbow 8》 and «Roundhouse Kick 8» by middleweights, and «Straight Kick 8» by heavyweights.
In the specialised test «40 seconds», the difference in shifts of indicators was found in one striking technique «Series of Jabs 40», a significant contribution to which was made by athletes of the lightweight category. The indicator of the total number of strikes by athletes of the heavyweight category in the striking technique «Series of Jabs 40» was reduced to the opposite result, which turned out to be statistically insignificant in the general experimental group. The growth of the speed-strength potential of the athletes from the experimental group over the athletesfrom the control group, without taking into account weight categories, is noted in three types of special ised tests of anzerobic capabilities with creatinephosphate and glycolytic mechanisms of energy supply, in the form of speed and power components, both individually and in unity.

\section{Conclusions}

1. The growth of the speed-strength potential of the lightweight category athletes from the experimental group in the considered striking techniquesismanifested in all types of specialised tests, in the form of speed and strength components separately.

2. The growth of the speed-strength potential of the athletes of the middleweight category from the experimental group in the noted striking techniques, manifested in specialised tests of creatine-phosphate performance, in the form of the unity of the speed and strength components, as well as separately only the speed component.

3. The growth of the speed-strength potential of the athletes from the heavyweight category of the experimental group in the considered striking techniques is manifested in all types of specialised tests, in the form of speed and strength components, both separately and in unity.

4. The growth of the speed-strength potential of the athletes from the experimental group in comparison with the athletesfrom the control group, without taking into account weight categories, is noted in three types of special ised tests of anzerobic capabilities with creatinephosphate and glycolytic mechanisms of energy supply, in the form of speed and strength components, both individually and in unity.

The results of the study can promotetheintroduction of differentiated programs with the use of the Podhurskyi's weight modified sports equipment in the main part of sportstraining of speed-strength orientation for qualified Muay-Thai athletes. This will allow for a 
more effective organisation of the training process in theimprovement and implementation of speed-strength abilities, taking into account group individualisation. Further research is assumed to reveal the absolute and relative growth of speed-strength capabilities in athletes of different weight categories. In turn, this will make it possible to improve the content of sports training of speed-strength orientation in regulating the growth of speed and strength components, both separately and in unity.

\section{Acknowledgements}

Scientific and methodological support in the form of mathematical data processing was provided by Professor, Doctor of Biological Sciences Mykhailo Yuriovych Antomonov. Assistance in providing a gym equipped with the necessary sports equipment and a team of active qualified athletes of all weight classes was provided by the president of the Muay Thai Spirit Gym sports club, Vyacheslav Lozenko.

\section{References}

Anttila, E., Siljamäki, M., \& Rowe, N. (2018). Teachers asfrontline agents of integration: Finnish physical education students' reflections on intercultural encounters. Physical Education and Sport Pedagogy, 23(6), 609-622.

Ball, S.J. (2019). A horizon of freedom: Using Foucault to think differently about education and learning Power and Education, 11(2), 132-144.

Dashiev, A.B., \& Aksenov, M.O. (2013). Improvement of special physical fitness of athletes-martial artiss using the «kicktest- 9 » power meter. Ulan-U de: Publishing House of the Buryat State University.

Gasanova, S.F., \& Lysenko, E.N. (2017). Features of the manifestation of special working capacity in qualified womenboxers in anaerobic conditions of carrying out loads. Sports Medicine and Physical Rehabilitation, 2, 46-54.

Hykso: The U ItimateTool for Fighters. (2020). Retrieved from: https:/ / www.hykso.com/.

Kamaev, O., Mulyk, V., Kotliar, S., Mulyk, K., Utkina, 0., Nesterenko,A., Sidorova,T.,Toporkov,A., \& Grynova,T. (2020). $O$ ptimization of the functional and speed-strength training of qualified skiers-racersduringthepreparatory period. Journal of Physical Education and Sport, 20(1), 131-137.

Krutsevich, T.Yu. (2012). Methods of physical education of different groups. Kyiv: 0 lympic Literature.

Kuzmenko, A.A., Kim, T.K., \& Kuzmenko, G.A. (2019). Junior icehockey players' special physical fitnesstests: Updateoptions. Theory and Practice of Physical Culture, 5, 94-96.

Maidanyuk, O.V., \& Ostyanov, V.N. (2011). Control of special physical fitness of qualified boxers of different weight categories. Acual Problems of Physical Culture and Sports, 1, 4449.

Martins, Ju., Cardoso, J., Honório, S., Silva, A. (2020).Theeffect of a strength training programme in adolescents in physical education classes. Retos, 38, 71-46.

Moreira,A.,Arsati, F., LimaArsati,Y.B., Franchini, E., \& DeAraújo, V.C. (2018). Effect of a kickboxing match on salivary cortisol and immunoglobulin. A Percept Motor Skill, 1, 158-166.

O khlopkov, P.P., Cherkashin, I.A. \& \& Krivoruchenko, E. V. (2018). Significant components of physical fitness of athletes of lightweight cotegoriesinThai boxingatthetrainingstage. Scholarly Notes of Lesgaft National State University of Physical Education, Sport and $H$ ealth, 2(156), 273-278.

Pavelets, A. Ya., O styanov,V.N., \& M aidanyuk, E.V. (2013). Model char acteristicsasthebasisfor individualisation of training boxers of the highest ranks (elite). Pedagogy, Psychology and MedicoBiological Problems of Physical Education and Sport, 10, 52-55.

Podhurskyi, S.E. (2017). Patent of U kraine for industrial design UA 35866. Sports equipment «Weight Podgursky» No. s201701299; declared 14.07.2017; publ. 12/ 11/ 2017.

Podhurskyi, S.E. (2018). Featuresof competitiveactivity of qualified thletes of different weight groups in Thai boxing Theory and Methods of Physical Education and Sports, 4, 31-35.

Podhurskyi, S.E. (2019). «Weight of Podgursky» as an effective means of improving the physical fitness of athletes. Scientific Journal of the National Pedagogical Dragomanov Universty. Series 15: Scientific and Pedagogical Problems of Physical Culture(Physical Cultureand Sports), 1, 73-79.

Podhurskyi, S.A. (2020). Performance of striking techniques among qualified M uayThai athletes of different weight classes International Journal of PerformanceAnalysis in Sport, 20(2), 294304.

Silva, J.J.R, Picanço, L.M. ., \& DelVecchio, F.B. (2010).Two proposals for the analysis of temporality in percussion fights, style K1. Revista Brasilera de Ciência e M ovimento, 4, 250-258.

Silva, J.J.R. (2011). Time-motion analysisin M uay-Thai and KickBoxing amateur matches. Journal of H uman Sport and Exercise, 6(3), 490-496.

Turmanidze, A.V. (2019). Characteristics of strength and speedstrength capabilities of muscles in Elite Badminton players. Theory and Practice of Physical Culture, 8, 8-12.

Vachev, S. \& \&urlo, 0. (2011). Comparative analysis of thelevel of specialised performancein shock techniques of Thai boxers of mass discharges Young Sports Science of U Kraine: A Collection of ScientifidWorks in the Fiedd of Physical Education, Sports and Human Health, 15(1), 42-47.

Viciana, J., Casado-Robles, C., Pérez-M acías, L., M ayorga-Vega, D. (2020). A sport education teaching unit as a citizenship education strategy in physical education. A group-randomized controlled trial. Retos, 38, 44-52. 